\title{
2016: het jaar van de Olympische Spelen in Brazilië
}

\author{
Barbara M. A. Schout ${ }^{1}$ Ad Hendrikx ${ }^{2}$
}

Published online: 9 November 2016

(c) The Author(s) 2016. This article is available at SpringerLink with Open Access.

Alle deelnemers aan de Olympische spelen willen trainen en door hun coach getoetst worden op kwaliteit. Ze willen niet alleen deelnemen, maar ook een plak: brons of zilver, maar het liefst goud. Ze werken er dagelijks aan om het bereikte niveau vast te houden of zelfs steeds verder te verbeteren. Ze streven in de wedstrijden en finales, die soms maar een paar minuten of enkele uren duren, naar landelijke, Europese en wereldrecords. Ze willen schitteren. Dat is de trots van een professional.

Ook urologen willen als professionals graag goede kwaliteit leveren. Ook zij gaan voor goud! Ze willen het beste voor hun patiënten en willen daar goed voor opgeleid en getoetst worden in hun opleiding. Ze willen ook graag dat niveau vasthouden, zichzelf ontwikkelen en verbeteren.

Het publiek ziet graag dat 'hun' artsen als besten uit de wedstrijd komen en 'hun' ziekenhuis als hoogste eindigt in de ontelbare lijstjes waarin bepaalde kwaliteiten langs de lat gelegd worden. Mensen willen inzicht hebben in de kwaliteit van zorg, ze willen de medaillespiegel zien en zelf kunnen kiezen waar ze heen gaan voor hun behandeling.

De vraag is: hoe bereiken professionals de komende vijf jaar dit optimale niveau en hoe houden ze dat niveau vast? Welke trainingen en toetsen in de urologie zijn daartoe nodig? Wat van het huidige trainingsaanbod moet nog aangescherpt, uitgediept en aangevuld worden? Hoe gaat de opleiding tot uroloog er precies uitzien?

\footnotetext{
dr. Barbara M. A. Schout

bschout.uro@gmail.com

1 Alrijne ziekenhuis, Leiden/Leiderdorp/Alphen aan den Rijn, Nederland

2 MEDEC, Nuenen, Nederland
}

In dit nummer van het Tijdschrift voor Urologie zijn vele van deze vragen aan de orde geweest en geven de auteurs ook zo veel mogelijk antwoorden op deze vragen.

Het curriculum voor de opleiding tot uroloog is op dit moment in revisie, onder leiding van professor Meuleman. Voor de toekomst is het belangrijk dat niet alleen het onderwijs en de training worden geoptimaliseerd en gereguleerd, maar dat er ook oog is voor een nieuwe vorm van toetsing. We zullen steeds opnieuw het doel van een toets moeten bepalen, formatief of summatief, en een bij dat doel passende toetsmethode moeten kiezen, zoals beschreven door de medische onderwijskundige experts Van der Vleuten en Van Merrienboer. Videoanalyse, waar Goldenberg en Grantcharov over schrijven, zou heel goed in de toekomst een van dé toetsmethoden kunnen worden. Patiëntveiligheid zal niet zozeer een impliciete, maar een meer expliciete rol in de opleiding moeten spelen. Van Verweij en collega's krijgen we daar een aantal handvatten voor. De termen entrustable professional activities (EPA), oftewel de kritische beroepstaak, en het Urologisch Vaardigheids Onderwijs (UVO) zullen na dit themanummer voor niemand meer onbekend moeten zijn. Deze toets- en trainingsmiddelen sluiten volledig aan bij nieuw en modern onderwijs, waar iedereen in de toekomst ook mee te maken zal krijgen.

Ook binnen het Concilium en de Jonge Urologen Commissie (JUC) zullen subspecialisatie en samenwerking bestaan. Dé algemeen uroloog zal in de toekomst niet meer bestaan. Door maatschappelijke ontwikkelingen van centralisatie en ontwikkeling van expertise op deelgebieden zijn deze begrippen, die vroeger minder belangrijk waren, nu essentieel geworden in het beleid van maatschappen en ziekenhuizen. Wellicht zijn er over vijf jaar regionale visitaties. Wellicht wordt de opleiding steeds vaker onderbroken door zwangerschaps- of ouderschapsverlof of sabbaticals. Wellicht komt in de toekomst iedere aios met gemak aan 
de 20 OSATS-beoordelingen per jaar en hanteren we daarnaast ook nog allerlei andere toetsmethoden, die allemaal rond diverse EPA's zijn gecentreerd. En wellicht worden delen van de voor de ene aios 5 jaar durende en voor de andere aios 5,5 jaar durende opleiding, gedaan in expertisecentra die nu nog geen opleidingsbevoegdheid hebben of een specifieke subspecialisme-opleidingsbevoegdheid krijgen ...

"It always seems impossible until it is done ..." Nelson Mandela
Open Access This article is distributed under the terms of the Creative Commons Attribution 4.0 International License (http:// creativecommons.org/licenses/by/4.0/), which permits unrestricted use, distribution, and reproduction in any medium, provided you give appropriate credit to the original author(s) and the source, provide a link to the Creative Commons license, and indicate if changes were made.

dr. Barbara M.A. Schout uroloog

dr. Ad Hendrikx uroloog 